\title{
EXPLORING THE INFLUENCE OF LAND RECLAMATION ON SEDIMENT GRAIN SIZE DISTRIBUTION ON TIDAL FLATS: A NUMERICAL STUDY
}

\author{
Lei $\mathrm{CHEN}^{1,2}$, Zeng ZHOU ${ }^{1,2, *}$, Mengpiao $\mathrm{XU}^{2}$, Fan XU ${ }^{3}$, Jianfeng $\mathrm{TAO}^{2}$, Changkuan ZHANG ${ }^{2}$ \\ We explore the effects of land reclamation on the morphological evolution and sediment sorting on a tidal flat using a \\ state-of-the-art numerical model (Delft3D). Consistent with existing field observations and analytical theories, model \\ results indicate that the longitudinal profile adjusts itself converging to new equilibrium states (narrower and steeper) \\ after a series of reclamations. Relatively fine sediments deposit adjacent to the sea dike, due to the flood-dominated \\ tidal hydrodynamics. The amount of sediment deposition in front of the dike peaks when the dike is designed at mean \\ sea level. After sequential reclamations, sediment grain size appears to be coarser offshore and on the tidal flat. Overall, \\ this study suggests that land reclamation can lead to the readjustment of tidal flat profile shapes and coarsening of \\ sediment grain size, which should be taken into account when reclamation projects are planned.
}

Keywords: land reclamation; sediment sorting; numerical; tidal flats

\section{Introduction}

Tidal flats, located at the junction of the land and ocean, are periodically emerged and submerged under the action of tides. The evolution of tidal flats is affected by a variety of natural (e.g., tides, wind waves, sediment, sea level rise and biological action) and anthropogenic processes (e.g., land reclamation, harbor building and fish farming) operating over different temporal and spatial scales (Amos, 1995; Friedrichs, 2011; Wang et al., 2012; Coco et al., 2013; Zhou et al., 2015). Sediment transport is an important intermediate process to link the morphological evolution of tidal flats with these forces. The sediment composition of tidal flats is various and each sediment type responds differently to forces so that sediment grain size distribution is complex but regular. Well-documented field observations on a number of tidal flats worldwide suggests that the sediment grain size exhibits a "landward fining" phenomenon characterized typically by the presence of finer mud and silt on the upper tidal flat while coarser sand on the middle-lower tidal flat (Flemming and Nyandwi, 1994; Friedrichs, 2011). Numerical results demonstrate that natural processes play different roles in sediment sorting dynamics (Zhou et al., 2015; Zhou et al., 2016). For example, tides and waves favor landward and seaward transport of fine sediment, respectively, resulting in convex and concave profiles.

Because of potential land resources of tidal flats, land reclamation has been a major human activity along coastal zones worldwide since the last century (Portnoy and Giblin, 1997; Gu et al., 2007; Li et al., 2013). The reduction in intertidal area due to land reclamation can modify the local hydrodynamics, e.g., reducing tidal volume, water flushing rates, and the water's ability to carry sediment (Jing et al., 2007; Gao et al., 2014). In the Bohai Sea, Yellow Sea and East China Sea, large-scale reclamations result in a rise in tidal amplitude which may enhance the probability of coastal hazards such as storm surges (Song et al., 2013). Flemming and Nyandwi (1994) indicate that land reclamation and dike construction have produced a steeper than normal energy gradient along the shoreward margin of the Wadden Sea, which substantially inhibits or prevents the deposition of sediments with settling velocities smaller than 0.5 $\mathrm{cm} / \mathrm{s}$. Wang et al. (2012) find that land reclamations influence tidal flat morphodynamics significantly, even leading to abrupt and irreversible changes. The ecological resources are another important feature of tidal flat but suffer from dramatic loss (Spencer et al., 2017; Li et al., 2018; Wu et al., 2018) and land reclamation is a major negative factor that leads to coastal wetland loss and degradation (Tian et al., 2016).

However, the impacts of land reclamation on sediment sorting dynamics of tidal flats have been rarely addressed by numerical models and are the focuses of this study, in which, we explore the effects of land reclamation on morphological evolution and grain size distribution of tidal flats using an opensource morphodynamic model (Delft3D). Specific research objectives include: (1) the effect of different designed locations of sea dikes on sediment sorting dynamics; (2) the effect of sequential reclamations on tidal flat profile shapes. By addressing these objectives, we aim to gain fundamental insight into the tidal flat morphodynamics under the impact of land reclamation to provide scientific basis for sustainable coastal zone management.

1 Jiangsu Key Laboratory of Coast Ocean Resources Development and Environment Security, Hohai University, Nanjing, China

2 College of Harbour, Coastal and Offshore Engineering, Hohai University, Nanjing, China

3 State Key Laboratory of Estuarine and Coastal Research, East China Normal University, Shanghai 200062, China

*Corresponding author: Dr Zeng Zhou, Email: zeng.zhou@hhu.edu.cn 


\section{Method}

The morphodynamic model Delft3D-FLOW is consisted of several modules describing flow dynamics, sediment transport and morphological changes. The bed-stratigraphy module, which can keep tracking the temporal and spatial distribution of multiple sediments, is switched on. We design several numerical experiments using the intensely-reclaimed tidal flats of Jiangsu Province, China as an example (Wang et al., 2012). Below, we first briefly introduce the model and then detail the model setup.

\subsection{Tidal currents, wind waves and bottom shear stress}

Following previous studies (Roberts et al., 2000; Zhou et al., 2015), we assume alongshore uniformity and adopt the one-dimensional shallow water equations to simulate the tidal flow. The continuity and momentum balance equations are

$$
\begin{aligned}
& \frac{\partial \eta}{\partial t}+\frac{\partial(h u)}{\partial x}=0 \\
& \frac{\partial u}{\partial t}+u \frac{\partial u}{\partial x}=-g \frac{\partial \eta}{\partial x}+v \frac{\partial^{2} u}{\partial x^{2}}-g \frac{u|u|}{C^{2} h}
\end{aligned}
$$

where $\eta$ is the water level with respect to datum (e.g., MSL) (m); $t$ is the time (s); h is the water depth $(\mathrm{m}) ; u$ is the depth-averaged velocity in the $x$ direction $(\mathrm{m} / \mathrm{s}) ; v$ is the horizontal eddy viscosity coefficient $\left(\mathrm{m}^{2} / \mathrm{s}\right) ; C$ is the Chézy friction coefficient $\left(\mathrm{m}^{1 / 2} / \mathrm{s}\right)$ and $g$ is the gravitational constant $\left(\mathrm{m} / \mathrm{s}^{2}\right)$.

The offshore open boundary is forced by a harmonic tide, which consists of $M_{2}$ and $S_{2}$, with a spring tidal range of $5.2 \mathrm{~m}$. The bottom shear stress induced by the tidal current is calculated as

$$
\tau_{c}=\frac{\rho g u^{2}}{C^{2}}
$$

where $\rho$ is the density of water $\left(\mathrm{kg} / \mathrm{m}^{3}\right)$.

In this model, wind waves are also simulated using the formulations of Young and Verhagen (1996a, b), which has been used by Fagherazzi and Wiberg (2009) to simulate the wind wave on tidal flats. We set the relevant parameters as $U_{\text {wind }}=2 \mathrm{~m} / \mathrm{s}$, wind fetch $=5000 \mathrm{~m}$ to create the wave. The wave-induced bed shear stress is typically calculated using a quadratic bottom friction

$\tau_{w}=\frac{1}{2} \rho f_{w} u_{w, b}^{2}$

$f_{w}=1.39\left[\frac{u_{w, b} T_{p}}{2 \pi\left(D_{50}^{\text {mix }} / 12\right)}\right]^{-0.52}$

where $\mathrm{k}$ is the wave number, $f_{w}$ is the wave friction factor given by Soulsby (1997) and $D_{50}^{\text {mix }}$ is the mean grain size of the sediment mixture which accounts for the volume.

Followed Soulsby (1997), the combined maximum bottom shear stress is simulated as

$\tau_{\max }=\tau_{w}+\tau_{c}\left[1+1.2\left(\frac{\tau_{w}}{\tau_{c}+\tau_{w}}\right)^{3.2}\right]$

This calculated bed shear stress is used to drive sediment transport and introduced in the following section.

\subsection{Sediment transport and bed stratigraphy modeling}

Both mud (cohesive) and sand (non-cohesive) sediments are considered in this study. The critical bed shear stress for erosion of mud is $0.2 \mathrm{~N} / \mathrm{m}^{2}$ and the median sediment diameter of sand is $100 \mu \mathrm{m}$. The initial layer thickness is $5 \mathrm{~m}$ and is constituted by $50 \%$ mud and $50 \%$ sand uniformly mixed and there is no external sediment input. The mud transport relation is based on widely-adopted PartheniadesKrone formulations (Partheniades, 1965) while for the sand, the Soulsby-vanRijn formulations (Soulsby, $1997)$ is used.

The bed dynamics of this model is according to the following procedure. The sea bed consists of three types of thin layers, which are the uppermost "active layer", several under layers and a base layer. In this model, the thickness of the initial active layer $\left(\delta_{a}\right)$ and under layers are set to $0.1 \mathrm{~m}$. Sediment in the active layer can be transported and is calculated using the previous formulas, but the value of $\delta_{a}$ limits the erosion in each time step. The key part of this procedure to achieve the vertical sorting of sediment is the interaction between the active layer and the under layer. At the beginning of next time step, if the 
thickness of the present active layer is smaller than $\delta_{a}$, it is replenished by the second layer and back to $\delta_{a}$, otherwise its excess part fills into the second layer if its thickness is larger than $\delta_{a}$. This procedure is repeated during the whole calculation (Zhou et al., 2015).

\subsection{Model setup and design of simulations}

As shown in Figure 1, we design two profiles as the initial bathymetry, which are a linear profile (1\%o slope) and an evolved profile resulting from the linear one without reclamation. Considering that the evolved profile is closer to reality, we use it as the final initial profile for the following simulation.

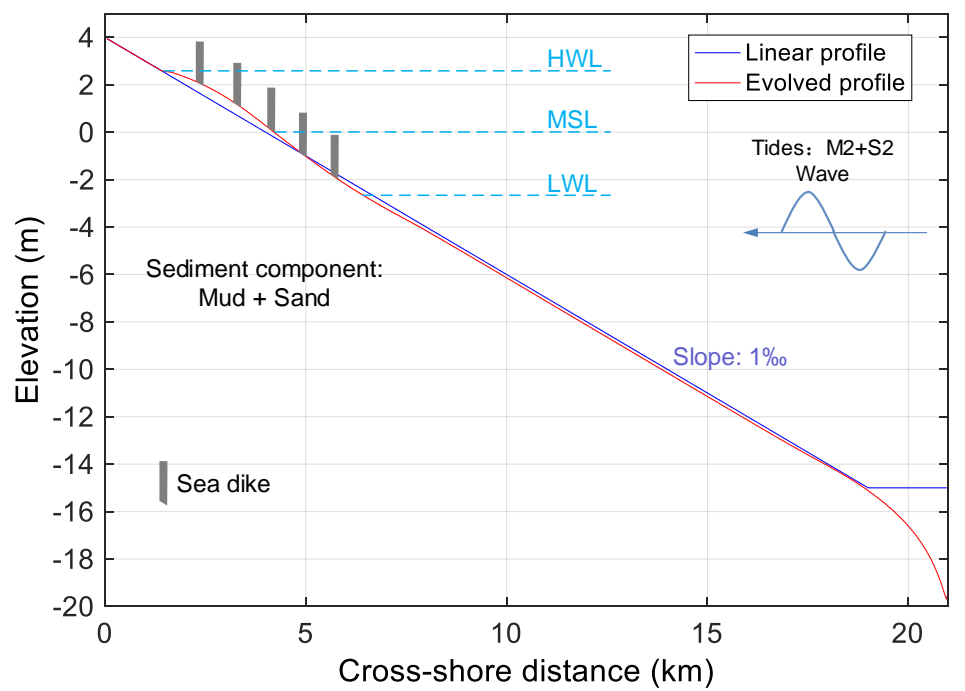

Figure 1. The initial profile and setting of the 1D model. Evolved profile is the model result without reclamation using the linear profile (a $1 \%$ slope) as the initial profile.

A computational grid with cell size of $50 \times 1000 \mathrm{~m}$ is used and the whole domain is $21 \times 1 \mathrm{~km}$. Simulation time is 200 years using a MorFac value of 10 , which can scale up the speed of the changes in the morphology to a rate that it begins to have a significant impact on the hydrodynamic flows, and time step is $0.5 \mathrm{~min}$.

The seaward limit of land reclamation is simulated using thin dams in the model, which are infinitely thin objects prohibiting flow exchange between the two adjacent computational cells without reducing the total wet surface and the volume of the model, so the area behind thin dams (landward) is reclamation area. We vary the location of the thin dam to study its effects on sediment grain size distribution (Figure $1)$.

\section{Results and Discussion}

Under the dominance of tides, the upper part of the tidal flat is convex and characterized by predominantly mud, while the lower part is occupied by sand (Figure 2a). After reclamation, the profile adjusts itself to a new equilibrium shape depending on the location of the sea dike. The main difference is reflected in the shape of accumulation in front of the dike. When the dike is located above the MSL, the upper part is convex but the middle-lower part turns to concave (Figure 2b, c). When the dike is located below the MSL, the upper part is concave because of the lack of sediment supply (Figure $2 \mathrm{~d}$, e, f). The reclamation affects the morphodynamics in front of the dike, enhancing the erosion at the middle flat and leading to deposition in front of the dike. The amount of sediment deposition is maximum when the dike is located at the MSL because if the dike moves landward, the sediment deposits area is larger and on the other hand, there is fewer sediment transport when the dike moves seaward (Figure 2b, c, d, $\mathrm{e}, \mathrm{f}$, the corresponding deposition thickness are respectively $0.13 \mathrm{~m}, 0.35 \mathrm{~m}, 0.47 \mathrm{~m}, 0.43 \mathrm{~m}, 0.04 \mathrm{~m}$ ).

After reclamation, the overall sediment grain size distribution in front of the dike still follows the landward fining behavior (Figure 2). However, the coverage range of the surficial mud varies considerably depending on the location of the sea dike. With MVF (mean mud volume fraction) $=0.01$ as the threshold (MVF $<0.01$ is considered to be no mud), the coverage range of each case are $4.70 \mathrm{~km}$, $2.70 \mathrm{~km}, 1.85 \mathrm{~km}, 2.50 \mathrm{~km}, 7.20 \mathrm{~km}$, respectively (Figure 3a), so the minimum value appears when the dike is located at MSL rather than $-2.0 \mathrm{~m}$. This is related to the hydrodynamics and sediment components in front of the dikes. When the sea dike is built at the elevation ranging from $0 \mathrm{~m}$ to $2 \mathrm{~m}$, the change of the total bed shear stress is small, which, for these cases, means that the coverage range only depends on 
the location of the dike. However, when the sea dike is built at the elevation of $-1.0 \mathrm{~m}$ and $-2.0 \mathrm{~m}$, there is a reduction in the total shear stress in front of the dike. As a result, the mud disperses instead of gathering in front of the dike (Figure 3b).

In general, the model results indicate that the tidal flat profile and the sediment sorting are affected by land reclamation. In particular, the location of the sea dike constructed for reclamation plays an important role.
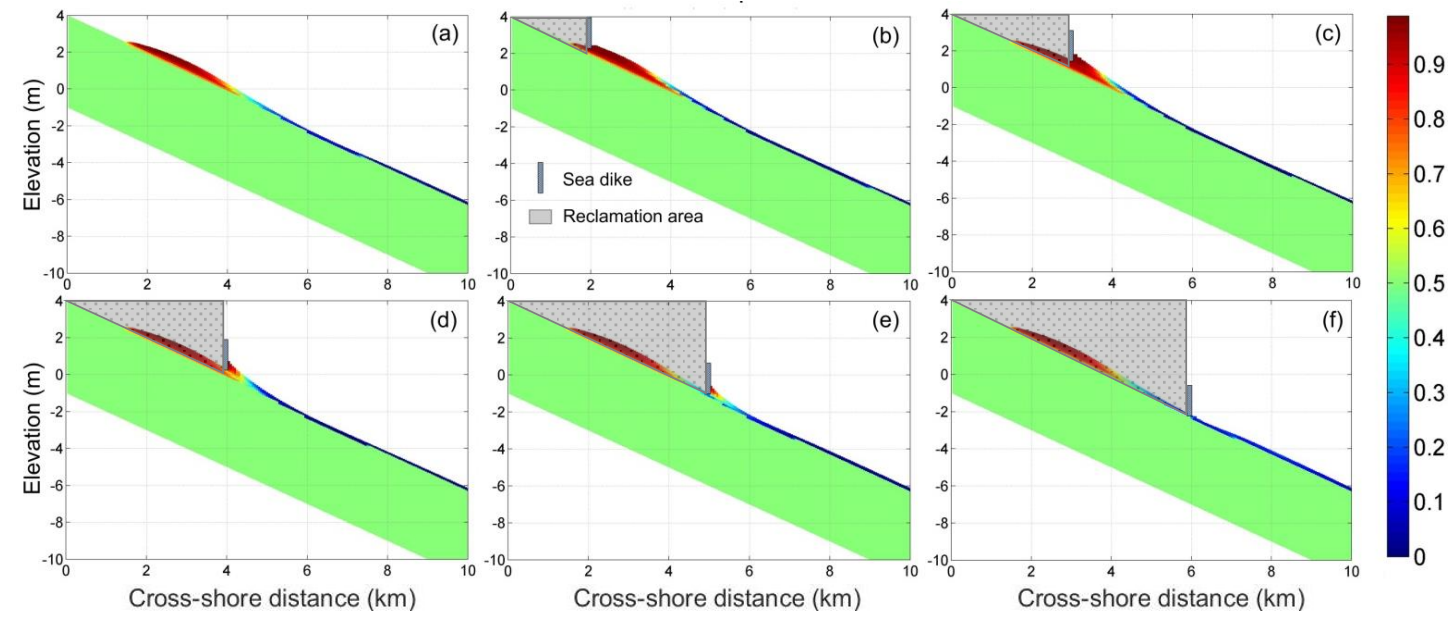

Figure 2. Simulated cross-shore distribution of sand and mud on a schematic tidal flat without reclamation (a) and with different locations of reclamations, (b) at $2 \mathrm{~m},(\mathrm{c})$ at $1 \mathrm{~m},(\mathrm{~d})$ at $0 \mathrm{~m},(\mathrm{e})$ at $-1 \mathrm{~m},(\mathrm{f})$ at $-2 \mathrm{~m}$ with respect to the MSL. The cases (b)(c)(d)(e)(f) simulated on the base of (a). The HWL is at $2.6 \mathrm{~m}$ elevation and LWL is at $2.6 \mathrm{~m}$ elevation. The color scheme indicates the volumetric percentage of mud fraction.
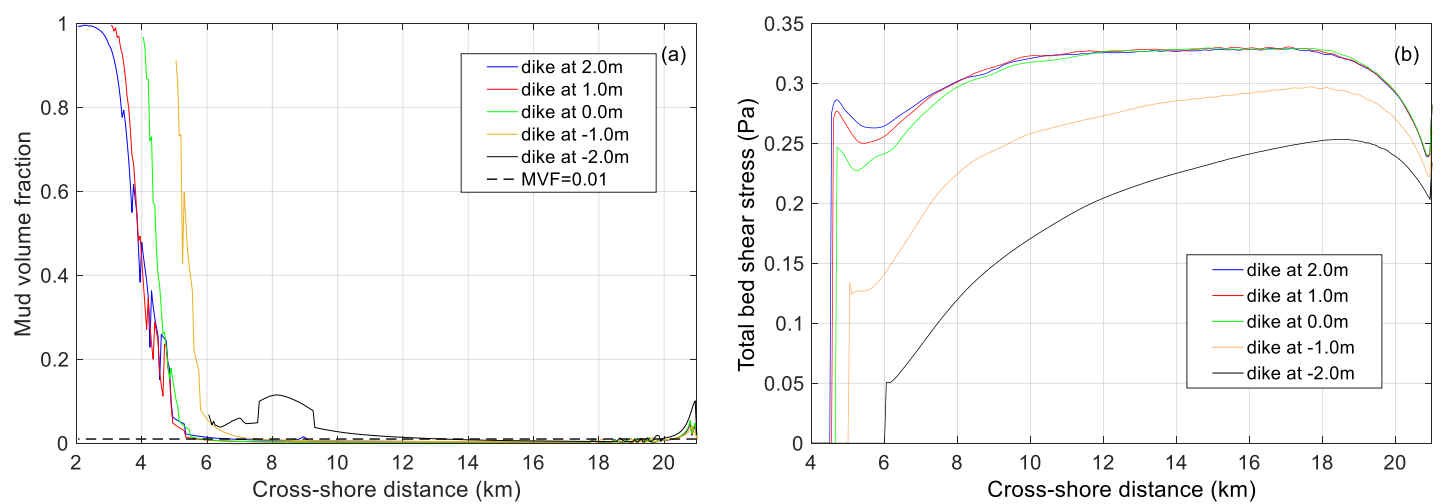

Figure 3. (a) Mean mud volume fraction (MVF) of the top three layers in sea bed (the width of each layer is 0.1 $\mathrm{m}$ ) and (b) total bed shear (tide-induced and wave-induced) after different locations of reclamations.

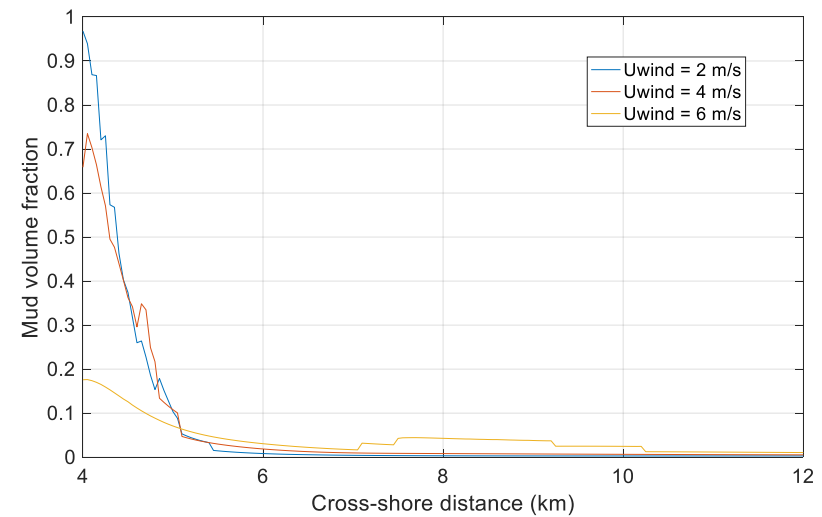

Figure 4. Mean mud volume fraction (MVF) of the top three layers in sea bed (the width of each layer is $0.1 \mathrm{~m}$ ) under different $\boldsymbol{U}_{\text {wind. }}$. All three dikes are located at MSL. 
Except the cases with $U_{\text {wind }}$ of $2 \mathrm{~m} / \mathrm{s}$, we also design the $U_{\text {wind }}$ of $4 \mathrm{~m} / \mathrm{s}, 6 \mathrm{~m} / \mathrm{s}$ and $8 \mathrm{~m} / \mathrm{s}$ to find out how waves influence model results. As shown in Figure 4, mud distribution responds little when $U_{\text {wind }}$ is small (e.g., $2 \mathrm{~m} / \mathrm{s}, 4 \mathrm{~m} / \mathrm{s}$ ) but if $U_{\text {wind }}$ is larger than $6 \mathrm{~m} / \mathrm{s}$, mud tends to be transported seaward, which shows the erosive nature of waves on fine sediment (Janssen-Stelder, 2000). In other words, after reclamation, the morphological respond of tidal flat to hydrodynamic forces retains its original features.

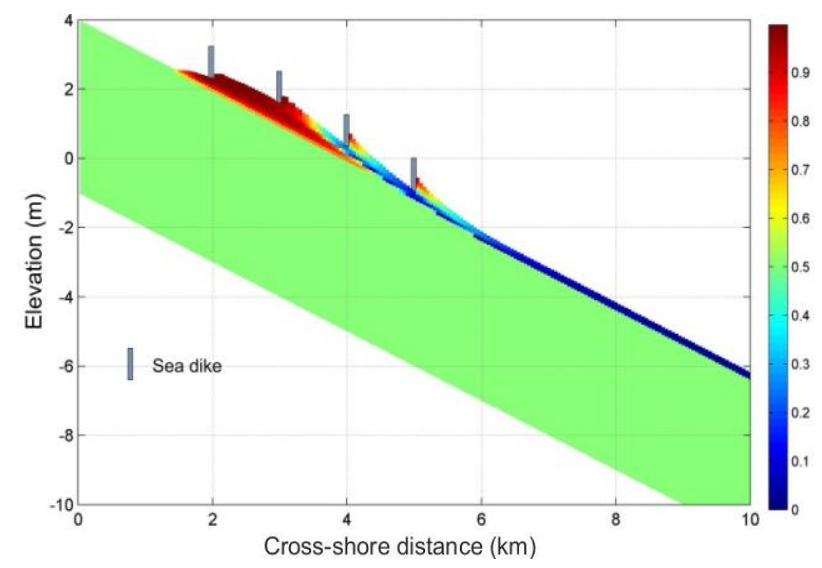

Figure 5. Simulated cross-shore distribution of sand and mud on a schematic tidal flat after sequential reclamation. The color scheme indicates the volumetric percentage of mud fraction.

Sequential reclamation model results show that there is always deposition in front of the dikes even without external sediment input (Figure 5). This is in agreement with field surveys conducted by Wang et al. (2012) who reported that the tidal flat after sequential reclamations adjusts to new equilibrium profiles which appear to be narrower and steeper and lead to stronger hydrodynamics. Besides, the deposition is mainly fine-grained sediment, which from the lower tidal flat, so that sediment grain size is more coarser offshore.

The change of sediment grain size distribution and stronger hydrodynamics destroy the ecological environment of tidal flat to a great extent (e.g., decreasing the salt marsh area and limiting its development). It is necessary to reclamation project reasonably. Base on the model results, reclamation should be managed with according to the state of the tidal flat: for erosive or stable one, reclamation should be moderate or limited; for cumulate one, human activities should also be under management. In addition, pre-restoration and pre-protection projects should be adopted at the same time for wildlife.

\section{Conclusion}

A state-of-the-art numerical model is used to explore the sediment sorting of tidal flat with a specific focus on land reclamation which has been rarely addressed by numerical method. The model results are consistent with existing field observations: Sediments tend to deposit in front of the dike after reclamation, such that the profile can approach a new equilibrium shape, which appears to be narrower and steeper under sequential reclamation. The sediment sorting tendency is not altered by land reclamation in which sediment becomes finer in the landward direction. In detail, when the dike is located on the elevation of MSL, the sediment deposition in front of the dike peaks, whereas the coverage range of the surficial mud is minimum. Besides, after sequential reclamation, sediment grain size appears more coarser offshore and even on entire tidal flat. The comparison between model results and field observations is successful in that a comparable sediment grain size distribution is achieved but the numerical model also exposes weaknesses in quantification and needs to consider more parameters (e.g., sediment input, salt marsh, sea level rise) and the interaction between them.

Overall, this numerical study demonstrates that the morphodynamic impacts of large-scale reclamations are manifold and their long-term consequences await more research effort.

\section{ACKNOWLEDGMENTS}

This study is supported by the National Key Research and Development Program of China (Grant No. 2018YFC0407501), the Natural Science Foundation of Jiangsu Province (Grant No. BK20160862), the National Natural Science Foundation of China (Grant Nos. 41606104, 51620105005).

\section{References}

Amos, C.L., 1995. Siliciclastic tidal flats. In: G.M.E. Perillo (G.M.E. Perillo)^(G.M.E. Perillos)|,*. 
Elsevier, pp. 273-306.

Coco, G., Zhou, Z., van Maanen, B., Olabarrieta, M., Tinoco, R. and Townend, I., 2013. Morphodynamics of tidal networks: Advances and challenges. Marine Geology, 346: 1-16, doi:10.1016/j.margeo.2013.08.005.

Fagherazzi, S. and Wiberg, P.L., 2009. Importance of wind conditions, fetch, and water levels on wavegenerated shear stresses in shallow intertidal basins. Journal of Geophysical Research, 114(F3): F03022-F03022, doi:10.1029/2008JF001139.

Flemming, B.W. and Nyandwi, N., 1994. Land reclamation as a cause of fine-grained sediment depletion in backbarrier tidal flats (Southern North Sea). Netherlands Journal of Aquatic Ecology, 28(3-4): 299307, doi:10.1007/BF02334198.

Friedrichs, C.T., 2011. Tidal flat morphodynamics: A synthesis. In: E. Eric Wolanski and D. McLusky (E. Eric Wolanski and D. McLusky $)^{\wedge}($ E. Eric Wolanski and D. McLuskys)|,*. Academic Press, pp. 137-170.

Gao, G.D., Wang, X.H. and Bao, X.W., 2014. Land reclamation and its impact on tidal dynamics in Jiaozhou Bay, Qingdao, China. Estuarine, Coastal and Shelf Science, 151: 285-294, doi:10.1016/j.ecss.2014.07.017.

Gu, D., Zhang, Y., Fu, J. and Zhang, X., 2007. The landscape pattern characteristics of coastal wetlands in Jiaozhou Bay Under the Impact of Human Activities. Environmental Monitoring and Assessment, 124(1-3): 361-370, doi:10.1007/s10661-006-9232-7.

Janssen-Stelder, B., 2000. The effect of different hydrodynamic conditions on the morphodynamics of a tidal mudflat in the Dutch Wadden Sea. Continental Shelf Research, 20(12-13): 1461-1478, doi:10.1016/S0278-4343(00)00032-7.

Jing, Y.U., Sun, Y.L. and Zhang, Y., 2007. Impact prediction of land-forming on marine environment in Jiaozhou Bay and Qianwan Bay I. Impact on hydrodynamic environment. Marine Environmental Science

Kearney, M.S., Riter, J.C.A. and Turner, R.E., 2011. Freshwater river diversions for marsh restoration in Louisiana: Twenty-six years of changing vegetative cover and marsh area. Geophysical Research Letters, 38(16): n/a-n/a, doi:10.1029/2011GL047847.

Li, X., Bellerby, R., Craft, C. and Widney, S.E., 2018. Coastal wetland loss, consequences, and challenges for restoration. Anthropocene Coasts: 1-15, doi:10.1139/anc-2017-0001.

Li, X., Sun, Y., Mander, Ü. and He, Y., 2013. Effects of land use intensity on soil nutrient distribution after reclamation in an estuary landscape. Landscape Ecology, 28(4): 699-707, doi:10.1007/s10980012-9796-2.

Partheniades, E., 1965. Erosion and deposition of cohesive soils. Journal of the Hydraulics Division, ASCE, 91(1): 105-139

Portnoy, J.W. and Giblin, A.E., 1997. Effects of historic tidal restrictions on salt marsh sediment chemistry. BIOGEOCHEMISTRY, 36(3): 275-303, doi:10.1023/A:1005715520988.

Roberts, W., Le Hir, P. and Whitehouse, R.J.S., 2000. Investigation using simple mathematical models of the effect of tidal currents and waves on the profile shape of intertidal mudflats. Continental Shelf Research, 20(10-11): 1079-1097, doi:10.1016/S0278-4343(00)00013-3.

Song, D., Wang, X.H., Zhu, X. and Bao, X., 2013. Modeling studies of the far-field effects of tidal flat reclamation on tidal dynamics in the East China Seas. Estuarine, Coastal and Shelf Science, 133: 147 160, doi:10.1016/j.ecss.2013.08.023.

Soulsby, R.L., 1997. Dynamics of marine sands: A manual for practical applications. Thomas Telford, London.

Spencer, K.L., Carr, S.J., Diggens, L.M., Tempest, J.A., Morris, M.A. and Harvey, G.L., 2017. The impact of pre-restoration land-use and disturbance on sediment structure, hydrology and the sediment geochemical environment in restored saltmarshes. Science of The Total Environment, 587-588: 4758, doi:10.1016/j.scitotenv.2016.11.032.

Tian, B., Wu, W., Yang, Z. and Zhou, Y., 2016. Drivers, trends, and potential impacts of long-term coastal reclamation in China from 1985 to 2010. Estuarine Coastal \& Shelf Science, 170: 83-90

Wang, Y.P., Gao, S., Jia, J., Thompson, C.E.L., Gao, J. and Yang, Y., 2012. Sediment transport over an accretional intertidal flat with influences of reclamation, Jiangsu coast, China. Marine Geology, 291 294: 147-161, doi:10.1016/j.margeo.2011.01.004.

Wu, W., Yang, Z., Tian, B., Huang, Y., Zhou, Y. and Zhang, T., 2018. Impacts of coastal reclamation on wetlands: Loss, resilience, and sustainable management. Estuarine, Coastal and Shelf Science, 210: 153-161, doi:10.1016/j.ecss.2018.06.013.

Young, I.R. and Verhagen, L.A., 1996a. The growth of fetch limited waves in water of finite depth. Part 
1. Total energy and peak frequency. Coastal Engineering, 29(1-2): 47-78, doi:10.1016/S03783839(96)00006-3.

Young, I.R. and Verhagen, L.A., 1996b. The growth of fetch limited waves in water of finite depth. Part 2. Spectral evolution. Coastal Engineering, 29(1-2): 79-99, doi:10.1016/S0378-3839(96)00007-5.

Zhou, Z., Coco, G., van der Wegen, M., Gong, Z., Zhang, C. and Townend, I., 2015. Modeling sorting dynamics of cohesive and non-cohesive sediments on intertidal flats under the effect of tides and wind waves. Continental Shelf Research, 104: 76-91, doi:10.1016/j.csr.2015.05.010.

Zhou, Z., Ye, Q. and Coco, G., 2016. A one-dimensional biomorphodynamic model of tidal flats: Sediment sorting, marsh distribution, and carbon accumulation under sea level rise. Advances in Water Resources, 93: 288-302, doi:10.1016/j.advwatres.2015.10.011. 